\title{
Itinerarios escolares y destinos sociales. El efecto de los juicios pedagógicos en trayectorias estudiantiles en Paraguay*
}

\author{
Luis Ortiz Sandoval ${ }^{1}$ \\ orcid.org/0000-0002-1902-8834 \\ Instituto de Ciencias Sociales de Paraguay
}

DOI: http://dx.doi.org/10.17081/eduhum.18.31.1378

Recibido: 15 de marzo de 2016

Aceptado: 25 de julio de 2016

\section{School timetables and social destinations. The effect of educational judgments in student trajectories in Paraguay}

Palabras clave:

Educación, Desigualdad social, Socialización, Destino social, Jerarquías.

Keywords:

Education, Social inequality, Socialization, Social destination, Hierarchies.

\begin{abstract}
Resumen
En los medios sociales desfavorecidos de Paraguay, la implementación de clasificaciones por la institución escolar se basa en la fijación de jerarquías de excelencia, que transforman los juicios pedagógicos en veredictos sociales para los estudiantes e incluso para sus familias. El objetivo de este escrito es mostrar cómo estos juicios involucran a los alumnos, docentes y padres, a lo largo del proceso educativo en los itinerarios que van desde la etapa preescolar hasta el final de la secundaria. El método empleado moviliza un abordaje cualitativo, basado en entrevistas calificadas. Los principales hallazgos revelan que el carácter temporal de la selección escolar convierte a los jóvenes -a través de su socialización- en alumnos excelentes o bien en alumnos relegados, con lo cual se refuerzan las jerarquías institucionales. A lo largo de las trayectorias, la escuela implementa las jerarquías que configuran la segregación social y que cumplen la función de legitimar las desigualdades sociales por la aceptación, de parte de los diferentes agentes del orden institucional, cuya lógica se muestra desconocida.
\end{abstract}

\begin{abstract}
Results of pedagogic judgments in the student's lifetime in Paraguay. In the poor social areas in Paraguay, the classifications implemented by schools is based on fixing hierarchies of excellence, which transform pedagogic judgments into social verdicts not only for students but also for their families. The aim of this writing is to show how these judgments involve students, teachers and parents, throughout the whole educative process in the student's lifetime from elementary to high school. The method used here is a qualitative one, based on qualified interviews. The main findings reveal that the temporary character of student's selection turn young studentsthrough their socialization- into excellent ones or else relegated to the background, thus reinforcing institutional hierarchy. All throughout the student's lifetime, the school implements the hierarchies that make social segregation and comply with the function of legitimizing social inequalities by the acceptance of different agents of the institutional order whose logic is still unknown.
\end{abstract}

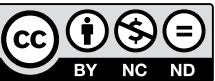

Referencia de este artículo (APA): Ortiz, L. (2016). Itinerarios escolares y destinos sociales. El efecto de los juicios pedagógicos en trayectorias estudiantiles en Paraguay. Revista Educación y Humanismo, 18(31), 257-273. http://dx.doi.org/10.17081/ eduhum.18.31.1378

* Artículo resultado en la línea de investigación Educación y desigualdad social del Instituto de Ciencias Sociales de Asunción, Paraguay.

1. Doctor en Sociología por la Escuela de Altos Estudios en Ciencias Sociales (París, Francia). Máster en Ciencias Sociales por la Facultad Latinoamericana de Ciencias Sociales (México D.F., México). Licenciado en Sociología por la Universidad Católica Nuestra Señora de la Asunción (Asunción, Paraguay). Profesor de esta casa de estudios y de la Facultad Latinoamericana de Ciencias Sociales (Sede académica Paraguay). Investigador del Instituto de Ciencias Sociales de Paraguay (ICSO Paraguay). Email: 1.ortizs@yahoo.com 


\section{Introducción}

Ya que no se puede justificar el éxito escolar sino explicando el sistema en el cual el éxito y el fracaso tienen sentido, proponemos con este artículo una aproximación del fenómeno que permite englobar a la vez lo que sucede "aguas arriba" de la relación pedagógica, en este caso la relación entre docentes y alumnos, y, "aguas abajo", es decir, los efectos de esta relación sobre los destinos sociales. El éxito escolar muestra así un hecho social total, pues implica un conjunto de condiciones de selección escolar pero también de selección social en el futuro educativo de los jóvenes. A este propósito, ciertas trayectorias desembocan en el éxito educativo y la larga escolarización, así como otras trayectorias culminan en el fracaso o en un "falso éxito", eufemismo del fracaso real aun cuando se cumpla la formalidad de obtener un título desvalorizado, porque se produce el abandono del sistema educativo una vez culmina el bachillerato.

Por tanto, una escolarización ejemplar, que desemboca en la prosecución de los estudios en la educación superior y en la consecución de un puesto de trabajo seguro, se fundamenta en la socialización, que juega un papel capital al momento de alcanzar los jóvenes uno u otro resultado en las trayectorias escolares. A lo largo del tiempo la socialización supone así un proceso de construcción de las disposiciones que van a impactar en los resultados escolares de los jóvenes, según los estados sucesivos del campo educativo y del proyecto de las familias. En este sentido, la relación de la familia con el tiempo escolar es un aspecto central ya que determina la participación de los padres en el trabajo pedagógico.

De esta manera la socialización conlleva una relación con el tiempo, que es fundamental para los proyectos familiares. Para algunos, con fuerte inversión escolar, la relación con el futuro será definida según la categoría de juventud estudiante, que tendrá el efecto de "distensión del lazo entre la formación y la situación social" (Chamboredon, 1991). Para otros proyectos, la categoría social de "juventud" implicará la temporalidad en la que la escolarización se ajuste a la elección de lo necesario. En uno y otro, la socialización está en la base de la selección educativa de los jóvenes.

Este artículo se basa en una investigación sobre el proceso de escolarización de jóvenes de clases desfavorecidas en dos medios sociales locales: un barrio de Asunción, capital del Paraguay, y un distrito de un departamento del norte del país, Concepción. La primera zona se ubica del barrio Ricardo Brugada, caracterizado por un entorno característico de pobreza y situado en la costa del río Paraguay. La segunda zona se trata del distrito de Belén, situado en el departamento de Concepción, distante a 420 kilómetros aproximadamente de la capital paraguaya.

\section{Problemática: socialización y selección}

Las diferencias de evaluación entre los alumnos no culminarían en desigualdades escolares si, como lo refiere Perrenoud (2003), en la escuela ellas no designaran sino diferencias de estilo, 
que están más o menos desfasadas con relación a las exigencias de la institución, por lo tanto, nada ineluctable. Pero desde que las diferencias evaluativas desembocan en desigualdades de trayectorias, alentando a unos a continuar los estudios universitarios e influyendo en los otros para sumergirse en un pesimismo acerca del futuro, las diferencias se convierten en diferenciación.

Las menciones escolares del tipo "mejor alumno", “excelente", “sobresaliente", etc., refuerzan antes que nada una visión que la escuela tiene de sus valores (Isambert-Jamati, 1966). Esta visión concierne tanto a los alumnos como a sus padres para construir, según los perfiles educativos, jerarquías que tendrán consecuencias en el porvenir. El etiquetaje que emana de los juicios de los docentes supone una dialéctica de subestimación y desestimación, cuyas prácticas de selección refuerzan las jerarquías escolares y las disposiciones a la autoeliminación (Becker, 2009). Por tanto, el éxito educativo, veredicto de la institución escolar, no se limita a los resultados surgidos de las pruebas o exámenes, o sea de la selección escolar, sino implica también un largo proceso de juicios supuestamente "neutros" en la interiorización de una relación con la institución escolar, lo que, igualmente, dispone a los alumnos a una relación más o menos tensa con el futuro (Lahire, 2008). La complejidad que implica para los docentes evaluar a los jóvenes que se parecen socialmente, les obliga a realizar clasificaciones arbitrarias y bien disimuladas. En este sentido, la trayectoria social de la familia puede convertirse de manera indirecta en trayec- toria de sus hijos, según el criterio que adopten los docentes para seleccionarlos.

Pocos alumnos y padres de alumnos se dan cuenta que los veredictos de las autoridades escolares, que desembocan en jerarquías de excelencia, son las principales causas de las diferencias de trayectorias sociales postcolegiales de los jóvenes. Este desconocimiento del verdadero proceso de relegación, forma disimulada de construcción de las desigualdades escolares y de reproducción de desigualdades sociales, es tanto más fuerte cuando las familias están desprovistas de capital cultural para aprehender su naturaleza. "La privación en materia de cultura no es percibida necesariamente como tal, el incremento de la privación acompañando al contrario de un debilitamiento de la conciencia de la privación" (Bourdieu, 1966, p.343).

Los alumnos excelentes, candidatos a volverse individuos "excepcionales", pertenecen a menudo a familias predispuestas a involucrarse, más allá de lo habitual, en el juego escolar para obtener cierto reconocimiento social. Este capital moral adquirido a lo largo del proceso de escolarización presupone la buena voluntad cultural de los padres. Haciendo esto, muchos entre ellos adquieren el conocimiento del proceso educativo, se hacen notar por los docentes exhortándolos hacia una buena evaluación y aprenden, con estos, ciertos saberes escolares y la relación con la cultura escolar. Los alumnos en cuestión pueden, más allá de la obtención del bachillera- 
to, ir a la universidad alentados por la (sobre) inversión de sus padres.

Al contrario, los alumnos "medios", bachillerato obtenido también, se ven a menudo obligados a entrar en el mundo del trabajo descontinuando la educación superior. Ellos ven su trayectoria truncada signada de indignidad y de torpeza, lo que les lleva a avizorar su destino como un verdadero fracaso. Durante sus trayectorias escolares muchos de ellos se ven tratados como "promedios". Su desempeño escolar no está sancionado por el juicio formal al final del colegio sino por el juicio social al inicio de la vida postcolegial. La nueva vida activa refuerza el orden social tal cual era antes del proceso educativo: desigual y altamente selectivo.

El origen social marca la disposición que cada joven tendrá al momento de interactuar con la institución escolar, así como define la consideración de la escuela hacia su escolaridad según el compromiso de los padres. Cuanto más escasos son los recursos de los agentes de clases populares, así mismo las diferencias mínimas de capital económico y cultural están llevadas a establecer las diferencias de trayectorias. La obtención del bachillerato conlleva grados de éxito educativo que son institucionalizados en una jerarquía escolar. Es esta jerarquía institucionalizada la que hace aceptable los destinos sociales expresados en la excepcionalidad de los alumnos excelentes y en la resignación de los alumnos "medios", quienes viven la relación con la escuela con sumo desinterés.
La resignación de los jóvenes a no comprometerse en estudios largos y a conformarse con su destino está reforzada en los grupos de pertenencia, sea de vecinos o de amigos de la misma generación, que a su vez ejercen una influencia sobre los primeros para aceptar su porvenir de clase como normal.

Esta dimensión fundamental del ethos de clase que es la actitud respecto del futuro, ¿no es ella, en efecto, otra cosa que la interiorización del porvenir objetivo que se recuerda y se impone progresivamente a todos los miembros de una misma clase a través de la experiencia de los éxitos y de los fracasos? Vemos que la influencia del grupo de pares (...) viene a redoblar entre los más desfavorecidos la influencia del medio familiar y de todo el ambiente social que tienden a desalentar las ambiciones percibidas como desmedidas y siempre más o menos sospechosas de suponer la negación de los orígenes (Bourdieu, 1966, p.333).

El origen social constituye un aspecto que pesa sobre la relación de los jóvenes con la escuela y con su futuro, pero nunca de manera directa. La trayectoria social de la familia y especialmente la inclinación de la trayectoria, hace la función de indicador (Bourdieu, 1974). La disposición al éxito, que es la relación de los jóvenes con su propia trayectoria escolar, marca la subjetividad de los alumnos, especialmente de los colegiales y los lleva a emprender estudios largos o bien a interrumpirlos y entrar enseguida en el mundo del trabajo. La inclinación de 
la trayectoria social actúa así a la manera de lo que Glen Elder llama las “ventajas y desventajas acumuladas" de manera que hace más o menos abierto el campo de posibilidades educativas según la antigüedad de apropiación de las competencias (Elder, 1998).

Entre las familias interrogadas para este estudio, algunas experimentaron un proceso de ascensión, que supone el pasaje del jefe de familia de una categoría socioocupacional a otra relativamente más elevada. Otras familias experimentaron un proceso de descenso. En el primer caso, las familias avizoran una larga escolarización para sus hijos, que están alentados a comprometerse con la escuela para garantizar la trayectoria ascendente de la familia y para asegurar su futuro. Se trata de los alumnos "excelentes" de nuestro estudio, para quienes la socialización tuvo por objetivo el desarrollo de la maestría en la relación con el futuro. En el segundo caso, las familias están más bien preocupadas de asegurar su reproducción y su torpeza respecto del juego escolar es patente. En ciertos casos, la trayectoria social implica el desplazamiento espacial de un lugar socialmente mal calificado a otro mejor calificado, o viceversa.

El aliento que los jóvenes reciben de sus padres opera, entonces, en forma de relación con el futuro. Se trata de la percepción que los jóvenes tienen de la trayectoria de sus familias. Si algunos experimentan el sentimiento de promoción, es porque sus familias tienen una trayectoria favorable y sus padres los empujan, por la vía de una ética rigorista, a sostenerla. En cambio, si ciertos jóvenes tienen una percepción de declive, es porque a menudo sus familias mismas tienen una trayectoria social desfavorable y, por consiguiente, sus padres no les exhortan a sostener una buena escolaridad; al contrario, les orientan, directa o indirectamente, hacia una "ética antijuvenil, que consiste en terminar la escuela y ganarse su sustento autónomamente" (Percheron, 1985, p.841).

\begin{abstract}
Incluso si es verdad que los temores y restricciones de los padres provocan a veces lo que pretenden impedir, que ciertos adolescentes son incapaces, en razón de las fobias y angustias que se les han inculcado, de sostener el prestigio social de la familia, no es para menos que las tensiones sociales son proyectadas sobre el psiquismo del joven por los gestos, preceptos y angustias de los padres (...), incluso si aún ignora la naturaleza de ello (Elías, 1987, p.320).
\end{abstract}

Resumiremos aquí las trayectorias de siete jóvenes cuyo origen social es similar, pero cuya relación con la trayectoria es disímil. Tres entre ellos poseen un sentimiento correlativo con las expectativas de ascenso de sus padres y su proyecto familiar adhiere, por tanto, a un modelo escolar de la juventud; cuatro entre ellos poseen un sentimiento correlativo al declive social de sus padres y su proyecto familiar en torno a la escuela se detiene donde la necesidad lo señale. Para unos y otros, la selección escolar tiene en cuenta la relación de cada alumno con su trayectoria, así 
como el "estatus parental", es decir, el peso que la presencia o ausencia de sus padres tiene en el proceso educativo.

\section{Recuento metodológico}

El método implicó la visita de relevamiento empírico en dos localidades, en dos regiones de Paraguay diferenciadas territorialmente. El enfoque, de carácter cualitativo, comprendió entrevistas narrativas a partir de las cuales los jóvenes que se seleccionaron como agentes típicos de cada localidad narraron sus trayectorias sociales y escolares. Los instrumentos fueron un listado con información de los hogares y guías de entrevistas con jóvenes, que permitieron objetivar sus rasgos sociales y económicos, así como sus características culturales, sus familias y sus escuelas.

La información relevada permitió aprehender la relación de las familias con el medio social inmediato, con la institución escolar y con la sociedad en general, facilitando la comprensión de las experiencias de escolarización, las trayectorias educativas y sus implicaciones en términos de sus orientaciones postescolares.

\section{Principales hallazgos}

Trayectorias contingentes y medios desfavorecidos

Analía D.L. tiene 19 años y concluyó el bachillerato. Pertenece al distrito de Belén del departamento de Concepción. Esta joven, cuya socialización fue encaminada para interiorizar el sentido de la responsabilidad, asume que su com- promiso será capital para el desenvolvimiento de su carrera futura de medicina que avizora. Aunque su familia no estuvo comprometida en un proyecto clásico de ascensión social, su relación con el porvenir está fundada sobre la seguridad moral que le dan sus padres, así como el sustento económico, de manera que ella y sus hermanas puedan movilizar el sentido de la responsabilidad y de la disciplina que fueron adquiridas en el hogar, para beneficio de diferentes ámbitos.

Analía D.L. es hija de un agricultor y vive en una "compañía" rural del distrito de Belén, con su padre, madre y dos pequeñas hermanas. Ella ve que su padre cuida su aspiración de ir a la universidad y la apoya para que cumpla su sueño. Ciertamente, dicho señor no está en condiciones de acumular recursos, pero el hecho de que incluso en tiempos de crisis asegura que las suyas vivan con dignidad y haga escolarizar a sus hijas, habla de una relación con la trayectoria social de su familia que es interiorizada por Analía. Según Faustina N., su madre, Analía aprendió el sentido de la responsabilidad dándose progresivamente cuenta del sacrificio de su padre y contribuyendo al sustento de la casa.

Analía nos ayudaba en la casa. Cuando yo tenía mucha necesidad de ayuda, ella me ayudaba a lavar la ropa, a cocinar y así... Todos los días ella me ayudaba un poco, pero cuando tenía mucho trabajo escolar, yo no la obligaba. A veces ella va a la chacra, porque su papá no tuvo un hijo (varón) que pudiera ayudarle. Yo también voy a menudo. A Analía no era nece- 
sario recordarle el estudio porque ella tomaba la iniciativa, con sus libros y estudiaba sin darnos a nosotros ningún motivo de preocupación. Así, ella daba ejemplo a sus hermanas más chicas, lo que es muy importante porque nosotros somos pobres; no tenemos otros medios, sino solo nuestra ayuda y apoyo como padres para que vaya adelante (Faustina de D.L., madre de Analía D.L., 19 años, Belén).

Aprendiendo todo eso, la joven incorporaba poco a poco la importancia de los estudios como un asunto "normal", de suerte que se puede desenvolver sola en la escuela y después incluso ayudar a sus pequeñas hermanas.

Yo ayudaba a Analía a hacer sus deberes cuando era chica, después ella trabajaba sola y a veces sus profesores le colaboraban, pero en general se desenvolvía para aprender sus lecciones; cuando no entendía al inicio, entonces sí preguntaba. Para nada era tímida, preguntaba si no entendía las lecciones, se desenvolvía muy bien, y era muy amiga de los docentes (Faustina de D.L., madre de Analía D.L., 19 años, Belén).

A medida que iba creciendo, Analía mantenía una trayectoria ejemplar, de manera que al culminar sus estudios secundarios estaba preparándose para el examen de ingreso a la Facultad de Medicina de la Universidad de Concepción, muy selectiva, por cierto. Durante toda su escolaridad supo mantener el equilibrio entre su vida estudiantil y su vida familiar, gracias a que su madre acompañaba su esfuerzo y su padre le daba el ejemplo de lo que M. Weber (1979) denominaba la "ética del trabajo".

Ella (Analía) quiere estudiar Medicina en la Universidad de Concepción. Su papá le dijo que si ella quiere estudiar, él le va a ayudar. Ella debe, para eso, ayudar también a su papá siendo trabajadora en sus estudios; es así, dice su papá, que ella va a ayudar a su familia. Él ayuda a su hija dándole apoyo financiero, ella trata de hacer lo mismo en los estudios (Faustina de D.L., madre de Analía D.L., 19 años, Belén).

Analía comprende que la continuidad de sus estudios será garantía para su persona, pero también para sus padres, que habrán hallado a través suyo la recompensa a sus esfuerzos: cuidarla y guiarla, de modo que fuera una joven tan respetable como sus pares de la ciudad, en fin, para que ella y su familia sean reconocidas.

En el pueblo de Belén, del departamento de Concepción, Julio M. tenía ganas de llegar lo más lejos posible en sus estudios. Pero poco después del deceso de su padre, cambió de decisión, queriendo hacer "otra cosa", o sea, no estaba seguro de lo que el futuro podía aportarle. Además, su madre lo empujó a buscar trabajo para ayudar a la familia.

Julio tenía al inicio buena voluntad para estudiar, pero la condición monoparental de su hogar trajo consecuencias negativas sobre su escola- 
ridad. A diferencia de Analía, cuya trayectoria social no tiene ninguna inclinación (hacia la promoción o hacia el declive), la familia de Julio está más bien en descenso social, razón por la cual su buena voluntad es débil y su relación con el futuro es de incertidumbre. A menudo los padres buscan proveer un diploma a sus hijos, pero en la realidad prefieren que se vuelvan adultos lo más temprano posible, ya que esto compromete su contribución económica con el grupo familiar o, dado el caso, a ser independientes de este.

Julio M. tiene 18 años y no concluyó el bachillerato. Es el mayor de cuatro hermanos: dos mujeres y dos varones. Él estudiaba en los establecimientos situados cerca de su casa, como el colegio “Carlos A. López”. Sin embargo, aunque no tenía muchos problemas en los estudios de primaria, su carácter era reservado, hablaba poco en clase, casi no se hacía notar por los docentes y tenía dificultad para trabajar en grupo.

Luego comenzó a "arrastrar" dificultades en el establecimiento, a veces no entendía a cabalidad el sentido de la distribución de las disciplinas de enseñanza ni la organización de los horarios de clase. En un momento dado de su itinerario, ocurre el deceso de su padre, que golpeó fuerte a Julio y a su familia. Después de este acontecimiento, dudó en continuar sus estudios; él avizoraba de culminar al menos su bachillerato, pero no lo logró. Cuando su padre murió, Julio perdió completamente el interés por los estudios al mismo tiempo que quedó obligado de ayudar a su familia.
Me gustaba estudiar, ir a la escuela, encontrarme con mis compañeros, todo eso, pero a veces durante las clases algunos profesores me pedían de participar y eso era difícil para mí porque yo no hablaba mucho... Si ellos me pedían hacer los deberes en mi casa, no había problema, ya que no me sentía cómodo participando en clase. Yo no era un "buen" alumno, pero no era malo tampoco... vamos a decir... "normal". Es cierto, si uno es tímido, cuando los profesores exigen demasiado, nos sentimos ofendidos... a veces era difícil (Julio M., 18 años, Belén).

Al final de cuentas, Julio comprendió que "no quería hacer estudios largos, sino trabajar". Ahora es peón de estancia en una finca ganadera a 36 kilómetros de Belén. Como él es el hermano mayor, está "obligado" a trabajar para ayudar a su madre y a sus hermanos menores. Mientras en este punto él es el sustento económico de su casa, Tania, su hermana del medio -en segundo año de colegio-, quiere seguir sus estudios en la universidad para intentar hallar un trabajo menos ingrato que el de su hermano. Ellos viven siempre en el pueblo donde tienen un pequeño hato de vacas lecheras de las cuales su madre y su hermana Tania ordeñan la leche para venderla a los vecinos y ganar así un poco de dinero.

Al igual que Julio, otros jóvenes del mismo medio social y que son hábiles para los estudios, podrían ir lejos en su proyecto de vida, pero ante las dificultades demasiado pesadas deben abandonar todo. De hecho, contextos como el pueblo 
o la campaña están privados de muchos servicios y ofrecen una situación económica precaria. Por tanto, cualquier situación nefasta como la que Julio y su familia debieron vivir, deja "fuera de juego". La pérdida de un solo miembro del grupo familiar puede arrastrar una ruptura de los lazos sociales. La obligación de arreglarse con pocos medios hace que los individuos sean sensibles al azar de la vida cotidiana para cumplir sus responsabilidades y su proyecto familiar.

En la ciudad, cuando las familias están socialmente en declive, la probabilidad de éxito de sus hijos en la educación secundaria es débil. Sin embargo, en ciertos casos, los jóvenes alcanzan el éxito a pesar de todo. El tipo de familia de estos jóvenes comprende padres que buscan ir más allá del porvenir de su clase social, tratando de controlar, en expresiones de Bourdieu, la causalidad de lo probable (Bourdieu, 1974). A menudo las expectativas ante la escuela se debilitan lentamente, aunque su legitimidad permanece igual. Después de la experiencia fracasada de sus hijos mayores, ciertos padres quieren ser más cuidadosos con los pequeños. La familia $\mathrm{G}$. nos muestra que, a pesar de la tendencia descendente de su trayectoria social, el éxito de uno de los hijos es el resultado de una ética rigorista, que siembra optimismo ante el sobreesfuerzo parental.

Gabriel G. tiene 18 años, concluyó el bachillerato y reside en el barrio Ricardo Brugada, de Asunción. Pertenece a una familia muy humilde. Su padre es plomero y trabaja en la empresa pú- blica que administra el servicio de agua potable en la ciudad. Este, proveniente de la campaña, llega a Asunción y trabaja en diferentes oficios durante mucho tiempo. Al momento de la entrevista hacía 18 años que trabajaba en su actual lugar de trabajo. Gabriel afirma que siempre le gustaron los estudios, pero que no era fácil mantenerlos: como a su hermana mayor y a su hermano menor no les interesaba estudiar, él no podía contar con ellos, y menos aún con sus padres para hacer sus deberes cuando había trabajos de la escuela. Cuando su madre se dio cuenta que él era bastante "hábil" respecto de sus hermanos, habló con los padres de alumnos vecinos, cuyos hijos eran compañeros de clase de Gabriel, para llevarlo de vez en cuando a trabajar con ellos. Eso no sucedía a menudo, pero era la manera como ella y el padre de Gabriel buscaban asegurar, tanto como se pudiera, la buena escolaridad de su hijo.

Mi hermana y mi hermano no estudiaron en la universidad, no... ellos dejaron. Mi hermana no terminó el colegio de hecho, mientras que mi hermano sí, pero después dejó todo. Mi hermana dice que quiere retomar sus estudios... quizás va a poder. A mí me gustaba mucho estudiar, yo nunca tuve problemas en el colegio. Nadie me ayudaba en mis deberes, o sea, de vez en cuando yo preguntaba a mi hermana, que me ayudaba, pero muy poco realmente; otras veces iba a estudiar con mis compañeros, pero si no podía, trabajaba solo no más en mi casa y me iba bien (Gabriel G., 18 años, Belén). 
Por este hecho, Gabriel no ayudó casi nunca en las tareas del hogar y no trabajó afuera. Se consagró completamente a los estudios y a través del tiempo, porque era buen alumno, sus padres le proporcionaban las mejores condiciones que podían para que fuera adelante. Por otra parte, cuando su hermana creció, dejó durante mucho tiempo la casa, celosa de esta "preferencia" de sus padres por Gabriel; a su vez, su hermano permaneció indiferente y no hacía gran cosa más allá de algunos pequeños trabajos para ganarse la vida y ayudar un poco a sus padres.

Mis padres me controlaban, eran exigentes desde siempre conmigo..., pero jamás me pegaron o maltrataron. Ellos no quieren que yo salga solo o que me junte con los jóvenes del barrio porque dicen que eso puede llevarme por mal camino; especialmente mi papá dice eso. Hoy es cierto que es muy peligroso el barrio..., pero de hecho no me gusta mucho salir, no me gusta ir a pasear en la "ciudad" ni nada... La única cosa que me gusta hacer es jugar fútbol de vez en cuando, y para eso mis padres me dan permiso...: cierto, a condición de respetar un horario de regreso a la casa enseguida (Gabriel G., 18 años, Belén).

Por otra parte, las rupturas familiares por causa del fracaso educativo llegan a menudo en las familias que, no teniendo la posibilidad de acompañar suficientemente a sus hijos, se culpan de su presunta torpeza o chocan entre padres e hijos, para echarse unos a otros la culpa del fracaso familiar. En el caso de Maura A., la experiencia del fracaso toca todo su hogar.
Maura A. tiene 19 años y no concluyó el bachillerato. Reside también en el barrio Ricardo Brugada y es hija de Sixto A. y Eulogia de A., dos migrantes rurales venidos a Asunción en búsqueda de trabajo. Su familia, compuesta de sus padres y cinco hermanas, vive desde hace 20 años en ese barrio. Desprovistos de capital cultural, sumergidos en el desconocimiento de la experiencia escolar, los padres de Maura no tuvieron las condiciones para acompañar a sus hijas en su escolaridad. Por este hecho, casi todas las hermanas, incluida Maura, abandonaron sus estudios antes de culminar el colegio, salvo la hija mayor.

Sixto A. era en su infancia un chico que vivió solo, deambulando entre parientes en la capital y sin haber tenido la oportunidad de crecer con sus padres. El sentido de "ir adelante" le hizo desarrollar un carácter "difícil" para defenderse solo. A veces era violento con sus hijas, especialmente con Maura, quien siendo la más pequeña, era en principio consentida por mucho tiempo. Cuando ella creció, desarrolló un estilo de comportamiento del tipo laissez faire, suscitado por la fragilidad moral de su barrio, la flexibilidad de la disciplina en su familia y el poco respaldo de parte de sus padres para desenvolverse bien en sus estudios. Según Sixto, Maura es "irresponsable" con respecto a sus tareas y no quería afrontar sola "hacer el esfuerzo de estudiar", lo que es de lamentar, dice él, ya que tanto este como su esposa se sacrificaron toda su vida para dar oportunidades a sus hijas. 
Soledad (Maura) no terminó sus estudios porque era una chica irresponsable, para qué vamos a decir otra cosa, por eso es. Ella tenía otra cosa en la cabeza. Y nosotros no podemos más 'actuar' por causa del sistema judicial actual. Habitualmente se le advierte a los niños de sus derechos y si por si acaso uno de sus padres quisiera "tocarles", es decir castigarles, bueno, se puede abrir un proceso contra él. Claro que nosotros no vamos a actuar con maldad sino solo para ponerles en su lugar... Este derecho que nosotros teníamos antes, no está en el sistema judicial actual. Entonces ellos, los niños, tienen más alas, son más "libres" y creen que pueden ya decidir bien. Y después, yo, a decir verdad, quería ejercer cierta autoridad sobre ella hasta que llegara a la mayoría de edad, porque yo sé que cuando ellos son grandes deben valerse por sí mismos.

Soledad más de una vez se fue de la casa... Sí, sí, se fue, alentada por sus amigos y por sus compañeros de colegio. Ella se va de aquí, después vuelve. Nosotros no le impedimos nunca volver a su casa, en nuestro "ranchito". Pero después cuando ella no está contenta afuera, le pedimos volver, pero que sea consciente. Ella volvió la última vez, pero no era más como antes: era más rebelde, no se callaba, y algunas veces simplemente se desentendía de nosotros. Yo le dije siempre a Soledad que terminara sus estudios de colegio, que lo más importante es terminar porque hoy es la única "arma" que uno puede tener para enfrentar a la vida. En la era moderna no es más el esfuerzo físico el que cuenta sino el esfuerzo intelectual, ¿verdad? Yo no sé, es mi opinión. Hay que tener vocación para estudiar... Yo, en mi época, ja la puta!, hacía mi esfuerzo, pero no tenía apoyo y ella (Maura) en cambio tiene nuestro apoyo y no hace ningún esfuerzo (Sixto A., padre de Maura A., barrio Ricardo Brugada).

Actualmente Maura no está más con sus padres. Sin título escolar y en plena ruptura con su familia, busca desenvolverse con pequeños trabajos tales como la venta de tarjetas telefónicas y como camarera en pequeños bares del centro de la ciudad. Su madre lamenta que no haya terminado el colegio, su padre deplora que no haya hecho estudios en la universidad. Ninguno de los dos vio en la falta de acompañamiento de Maura y de las otras hijas, ni tampoco en la interrupción de los estudios por parte de sus hermanas mayores (consentido por Sixto y Eulogia), una de las causas del abandono de la escolaridad de esta otra hija. Ninguno de los dos no vio tampoco la falta de incentivo al estudio que un barrio violento ofrece ni lo que el hacinamiento de su casa implicaba para ella.

Todas estas condiciones explican el bajo número de jóvenes que emprenden un trayecto universitario. En cuanto a los alumnos que la socialización dispuso a convertirse en notables ante sus familias mismas y excelentes ante la institución escolar, la seguridad vis-à-vis de la selección escolar se vuelve la condición de su autonomía pedagógica y se muestra crucial para 
continuar los estudios superiores. Estos jóvenes (Analía, Gabriel y otros) interiorizaron la pretensión de sus padres visualizando, por tanto, la ascensión social.

Por otra parte, las trayectorias escolares más corrientes llevan a la interrupción de los estudios y al desempleo, o desembocan en puestos subvalorados en la ciudad o en el trabajo agrícola en la campaña (Maura, Julio y otros). A excepción de algunos padres, que contestan tanto más fuerte los veredictos escolares injustos cuando no tienen nada que temer de la escuela, la mayoría de los progenitores de jóvenes cuya trayectoria es descendente, son indiferentes a sus juicios. A menudo la larga escolarización de los jóvenes de estas familias no está prevista y la escuela misma es cuestionada sin que, por tanto, ello implique actos de oposición. Pues para los jóvenes de los medios sociales desfavorecidos de Paraguay, la salida prematura de la escuela revela más una indiferencia con el proceso educativo que una "cultura de oposición a la escuela" (Willis, 1978, p.50). En todo caso, la conciencia de las familias de que detrás de la lógica institucional escolar hay relaciones de fuerza disimuladas, está en proceso de ganar terreno.

En resumen, por un proceso social de selección de las trayectorias, las desigualdades de inicio se transforman en desigualdades de resultado, ya que en los espacios segregados paraguayos hay afinidad electiva con los efectos de etiquetaje que los docentes y las autoridades implementan favoreciendo ciertos jóvenes y des- calificando otros. El mismo Jean Pierre Terrail (2002) lo evoca:

No es porque el etiquetaje social ejerce un efecto propio sobre la trayectoria de los alumnos que este efecto es independiente de su valor escolar, del desarrollo de sus aprendizajes, de sus relaciones con los saberes: es solamente en caso de fracaso, en todo caso, de dificultades escolares significativas, que los alumnos están expuestos a su acción (p.86).

Para ciertos jóvenes, de hecho, el porvenir se muestra incierto incluso antes del final del colegio, lo que los lleva a abandonarlo justo antes de obtener el bachillerato, o a obtenerlo e interrumpir los estudios. Son las dos vías del fracaso educativo en los medios desfavorecidos paraguayos. Tanto para Maura e Ivonne como para Julio y Eustaquio el hecho que la escuela dé cada vez menos oportunidades en la vida, se mostró en su realidad cruda antes del último año de la educación media. Sus padres, impotentes, no los incitan a continuar estudiando ante la ausencia de alternativas. Es más, le alientan a la deserción ya que desprovistos de chances ante el futuro, prefieren no asumir riesgos.

La interrupción de la carrera escolar de los jóvenes arrastra la vivencia de un verdadero fracaso y la culpa que atrae cuestiona, en ciertos casos, al conjunto del grupo familiar. Es tanto más frustrante para los padres cuando sus expectativas ante la escuela eran excesivas. Constatan la hipocresía escolar, más precisamente de las 
autoridades escolares, que incitan a todos los jóvenes a estudiar, pero favorecen -por su indiferencia a las desigualdades entre las familias- solamente a algunos de ellos para alcanzar el éxito.

\section{La relegación, destino proyectado}

Para los jóvenes y las familias que invirtieron en el campo educativo para ganarse, antes que nada, el reconocimiento social que los títulos les otorgarían, la impotencia de ver su esfuerzo caer en la nada con la obtención de títulos desvalorizados, los lleva a un fuerte desaliento respecto de las decisiones a tomar en el futuro. En cuanto al abandono de los estudios, si no es muy corriente, los jóvenes que estuvieron influidos por sus experiencias educativas individuales no ven su destino como trágico, sino como "natural", propio del conformismo de los agentes desprovistos de expectativas antes de iniciar su escolarización. Su resignación a la relegación escolar y a la segregación social es del orden de la "naturaleza de las cosas" de la cual el azar sitúa en su lugar, antes del proceso social, a los vencedores y vencidos, respectivamente, del juego escolar.

Por otra parte, la trayectoria de los jóvenes excelentes no puede ser explicada solamente por su aptitud para los estudios, sino también por su actitud respecto de la institución escolar, siendo crucial la participación de la familia. La correspondencia entre una trayectoria familiar de ascensión social y el éxito educativo excelente se convierte en lo que podemos denominar la trayectoria escolar legítima o escolarización normal, que implica la ascensión social de la familia, el acompañamiento de los padres en los estudios de los jóvenes, la participación en las actividades escolares de los hijos y la adquisición de un sentido de la responsabilidad para que estos puedan comprometerse en sus estudios. Para las familias en ascensión, la illusio del campo educativo, que consiste en creer en el juego escolar y jugarlo, alentando a sus hijos a emprender largos estudios, vuelve legítimo el sistema educativo.

Pero siendo tan exigentes las condiciones de una escolarización normal, el número de jóvenes correspondiente a una configuración de éxito es bajo. Los jóvenes que recorren la vía escolar legítima, que es de hecho la "buena trayectoria", son la excepción a la regla en los espacios segregados, donde la mayor parte de la población permanece pobre y marginalizada, excluida de los buenos efectos de la escolarización y decepcionada respecto del sistema educativo. Sea por mérito familiar e individual, sea en razón de la buena evaluación de la institución escolar, los jóvenes excelentes son los "elegidos" de una carrera escolar reservada a un pequeño número de alumnos que tienen la responsabilidad, mitad consciente mitad inconsciente, de sostener la ideología de la meritocracia y de la igualdad de oportunidades.

De hecho, la creencia en la promoción social, sobre todo extendida en las clases medias $\mathrm{y}$ en las capas superiores de las clases populares, hace que las familias inviertan en el campo educativo a falta de conocer la lógica del campo económico en el cual no quieren tomar riesgos de inversión. Los jóvenes se vuelven una suerte de capital simbólico que puede ser movilizado 
para acrecentar el capital social y el poder en una localidad.

Las desigualdades de itinerario escolar no se explican solamente por las diferencias de desempeño escolar de los alumnos. La naturaleza de las trayectorias en el sistema educativo paraguayo es, en este sentido, no meritocrática: no son solamente las aptitudes y competencias de los alumnos las que fundan su éxito, es decir, el mérito. Otros criterios tales como el estatus parental -que se traduce en un capital moral para los jóvenes- ejercen un efecto específico, tanto que, a competencias escolares comparables, los jóvenes cuyo capital moral es mayor aprueban con menos dificultades las examinaciones y aseguran su promoción a niveles superiores.

Mientras que la igualdad de oportunidades debía caracterizar al nuevo sistema educativo con la apertura y la retención para las clases populares, así como asegurar la asignación de las posiciones según criterios imparciales de evaluación, las desigualdades de trayectoria escolar, empero, distinguen a los diferentes medios sociales. Solamente una minoría de jóvenes de familias desfavorecidas, que comienza los estudios primarios, culmina la secundaria. En el curso de su escolarización, el sistema educativo los elimina por la vía institucional (la selección) o por las disposiciones (la autoexclusión) de modo que ellos "interiorizan su fracaso escolar como si fuera efecto del talento o la suerte" (Bourdieu \& Passeron, 1970, p.62), desconociendo la lógica de los etiquetajes y la relegación por origen social. Dado que el sistema educativo es de reciente data, los procesos de relegación y de eliminación no se hacen aún sentir como expresión de la distancia cultural y como confirmación del destino. La prolongación media de la escolarización está ligada a las formas diferidas de eliminación que son la sobre-edad y la repitencia, que desembocan en el rezago escolar en los niveles de estudio menos valorizados, directamente en relación con la restricción de las opciones de escolarización en los niveles más elevados y el acceso a los títulos más valiosos.

La descalificación escolar, resultado de las situaciones de precariedad de las familias y de la severidad de los juicios escolares, transfiere la responsabilidad de la relegación y la deserción educativa a los padres de alumnos, lo que exime a la escuela de su parte de responsabilidad en la desilusión de los jóvenes respecto de su porvenir. Ella contribuye de manera substancial a la descalificación social de muchos jóvenes que, por un lado, abandonan sus estudios y, por el otro, no ingresan al mundo laboral, o sea que permanecen en su "lugar" por prescripción de los veredictos escolares. Los docentes disimulan su connivencia con la reproducción de las desigualdades cuando pregonan ser solo los jueces de una "competencia justa".

Ciertos padres, con buena voluntad cultural y a pesar del desconocimiento de la experiencia escolar, alientan a sus hijos a aprender sus lecciones, a trabajar en clase y en casa, así como a adquirir el conocimiento escolar, no solamente para verse certificados en tanto alumnos sino también reconocidos como personas. "El capital 
moral es tanto más necesario cuando la escuela prepara a los estudiantes a aceptar la autoridad docente, bajo la condición que el joven vea sus derechos de persona privada reconocidos" (Benoliel \& Establet, 1991, p.12).

Por otra parte, los padres de alumnos que no culminan el colegio no se percatan de la injusticia de la institución escolar. La cultura escolar es entonces, por este hecho, una arbitrariedad cultural que se impone a las clases desfavorecidas, no como un currículo a dominar sino como un orden a respetar, que es más o menos riguroso según las características del público, la organización del establecimiento y las oportunidades objetivas de los jóvenes de clases desfavorecidas en el mundo del trabajo. Ya que algunos de estos, a pesar de su origen social, llegan lejos en su escolarización por su adecuación a la cultura escolar, los otros ven en esta disposición un "don natural".

La persistencia a través del tiempo de las desigualdades constituyó una trampa para la reforma educativa en Paraguay, desde un inicio. Reimers (1993) sostenía que la masificación del acceso y la prolongación de la escolarización en el sistema educativo desplazarían las desigualdades educativas durante la época autoritaria hacia otros modos de desigualdades (p.39), lo que autores como Bourdieu identifican como la translación de la estructura de desigualdad de oportunidades.

Las desigualdades de resultados surgidas de las configuraciones escolares se construyen en- tonces por la institución escolar, por la acción de los agentes que toman decisiones y afectan el destino social de los jóvenes. Todo sucede como $s i$ en el seno de la escuela se construyeran categorías de alumnos que desembocan en jerarquías desiguales de excelencia, tan antiguas como el sistema educativo mismo. De este modo, excelencia obliga: solamente los alumnos elegidos llegarán lejos. Las familias de clases desfavorecidas aceptan tanto más estas jerarquías cuando invierten para resultar, en ellas, favorecidas, o más precisamente, para que sus hijos alcancen los niveles más elevados del proceso educativo. Esta concertación tácita es el núcleo de la selección escolar que aventaja a los alumnos dóciles y dedicados, así como a sus padres, que adquirieron un estatus reconocido ante la escuela.

Casi nadie, salvo una joven, entre los antiguos alumnos de las clases desfavorecidas que fueron entrevistados para este estudio, eligió las carreras universitarias más selectivas en $\mathrm{Pa}$ raguay (Medicina e Ingeniería Civil), dado que son exigentes, largas y costosas, así como su dedicación es de tiempo completo (las clases son matutinas y vespertinas). Las formaciones cortas y menos selectivas en el nivel educativo superior son las que están mayoritariamente al alcance de los jóvenes de origen modesto mientras que los jóvenes de origen privilegiado están sobrerrepresentados en los estudios largos y costosos. Según la evolución de las tasas de acceso a los diferentes niveles educativos, especialmente el bachillerato, la desigualdad parece disminuir (Denis, 2005). Pero se corre el riesgo de "confundir la democratización de la enseñanza con 
la difusión ordinaria de un bien, no tomando en cuenta la eliminación diferida de los jóvenes de origen desfavorecido en los niveles educativos elevados" (Oeuvrard, 1979, p.95). Mientras el ingreso a la universidad está formalmente abierto a todos, el acceso a los estudios valorizados es objeto de una selección elitista.

\section{Conclusión}

Las diferencias de evaluación orientan los itinerarios escolares hacia desigualdades educativas, incentivando a unos a continuar los estudios superiores e influyendo en otros para caer en el pesimismo ante el futuro. Las diferencias, mínimas, se convierten en diferenciación, o sea, en desigualdades de resultados, por las prácticas de selección de los docentes quienes empleando una economía evaluativa, reducen la complejidad que implica examinar jóvenes socialmente similares. La arbitrariedad de la evaluación se basa, por lo general, en la trayectoria social de la familia que se vuelve un criterio a la vista de los profesores para clasificar a los alumnos en sus prácticas de evaluación.

La excelencia de los alumnos se construye también a partir de la propensión de las familias a involucrarse en el proceso. Los padres de familia adquieren conocimientos sobre la institución escolar, e impulsan a los docentes a una buena evaluación que redituará, más allá de la obtención del bachillerato, al ingreso a la universidad de sus hijos. En sus itinerarios educativos, varios jóvenes se ven tratados como medios según la trayectoria social de su familia, que no se orienta a valorizar la escuela ni el desempeño de sus hijos. Por lo tanto, el fracaso educativo no se define solo por la evaluación sino también por la trayectoria. La percepción de los jóvenes a propósito de la misma orienta hacia un camino de promoción educativa o hacia un camino de segregación. Las familias cuyos padres pretenden superar el porvenir probable de su clase social tienen mayores exigencias, lo que implica inversiones a base de renuncias y sacrificio. Estas condiciones explican las bajas tasas de éxito educativo, en los términos que hemos recorrido en este estudio.

En cuanto a los alumnos cuya socialización los dispuso a convertirse en notables ante sus familias y excelentes ante la institución escolar, adquirieron cierta autonomía pedagógica que los habilita a proseguir sus estudios en la educación superior. Dichos jóvenes interiorizaron la pretensión de sus padres de éxito social. Con la excepción de algunos padres, que pudieron ver los veredictos escolares como arbitrarios, la mayoría se muestra conforme a los juicios aun cuando desfavorecen a sus hijos. La descalificación escolar, resultado de las trayectorias sociales desfavorables de las familias y de la severidad de la escuela en sus juicios sobre ellas, inclina a la relegación a los grupos domésticos transfiriéndoles la responsabilidad de la relegación de sus hijos. A nivel general la descalificación lleva a los individuos de esas familias a aceptar su exclusión en los márgenes desfavorecidos de la sociedad. La educación participa en esa lógica social al movilizar mecanismos institucionales que operan con arbitrariedad. 


\section{Referencias}

Becker, H. (2009). Outsiders. Hacia una sociología de la desviación. Buenos Aires: Siglo XXI Editores.

Benoliel, R. \& Establet, R. (1991). "Jeunesse et habitus. Pertinence de l'hypothèse, impertinence des enquêtes". Enquête, La socialisation de la jeunesse. Recuperado desde http://enquete.revues.org/document 120. html

Bourdieu, P. (1966). L'école conservatrice. Les inégalités devant l'école et devant la culture. Revue française de Sociologie, 7(3), 325-347.

Bourdieu, P. (1974). Avenir de classe et causalité du probable. Revue française de Sociologie, 15(1), 3-42.

Bourdieu, P. \& Passeron, J. C. (1970). La Reproduction. Éléments pour une Théorie $d u$ système d'enseignement. Paris: Éditions de Minuit.

Chamboredon, J. C. (1991). Classes scolaires, classes d'âge, classes sociales. Les fonctions de scansion du système de formation. Enquête, La socialisation de la jeunesse. Recuperado desde http://enquete. revues.org/document144.html

Denis, M. (2005). Perfil de la Educación. Ciudad Fernando-De-la-Mora: DGEEC Publicaciones.

Elder, G. H. (1998). The Life Course as Developmental Theory. Child Development, 69 (1), 1-12.

Elías, N. (1987). El proceso de la civilización. néticas. México D.F.: Fondo de Cultura Económica.

Isambert-Jamati, V. (1966). La rigidité d'une institution: structure scolaire et systèmes de valeurs. Revue Française de Sociologie, 7(3), 306-324.

Lahire, B. (2008). La raison scolaire. École et pratiques d'écriture, entre savoir et pouvoir. Rennes: Presses Universitaires de Rennes.

Oeuvrard, F. (1979). Démocratisation ou élimination différée? Actes de la Recherche en Sciences Sociales, 30(1), 87-97.

Percheron, A. (1985). Le domestique et le politique. Types de familles, modèles d'éducation et transmission des systèmes de normes et d'attitudes entre parents et enfants. Revue Française de Science Politique, 35(5), 840-891.

Perrenoud, P. (2003). La construcción del éxito $y$ del fracaso escolar. Barcelona: Ed. Morata.

Reimers, F. (1993). Análisis del Sistema Educativo en el Paraguay. Sugerencias de politica y estrategias para su reforma. Asunción: CPES.

Terrail, J. P. (2002). De l'inégalité scolaire. Paris: Éditions La Disputa.

Weber, M. (1979). La ética protestante y el espiritu del capitalismo. Barcelona: Ed. Península.

Willis, P. (1978). L'école des ouvriers. Actes de la Recherche en Sciences Sociales, 24(1), 50-61. 